\title{
A Stability Indicating Validated Method for the Determination of Lercanidipine Using Reverse Phase High Performance Liquid Chromatography
}

\author{
Sumanta Mondal ${ }^{1 *}$, Reddipalli Pushpalatha ${ }^{1}$, Prasenjit Mondal ${ }^{2}$, Ashes Sinha Mahapatra', Dipankar Shit ${ }^{1}$, Anik Kumar Das ${ }^{1}$ and \\ Sabyasachi Biswal ${ }^{1}$ \\ 'Institute of Pharmacy, GITAM (Deemed to be University), Visakhapatnam, Andhra Pradesh, INDIA. \\ ${ }^{2}$ Vaageswari Institute of Pharmaceutical sciences, Ramakrishna Colony, Karimnagar, Telangana, INDIA.
}

\begin{abstract}
Objective: An accurate reverse phase High Performance liquid chromatography (RP-HPLC) method has been developed, validated and applied to stability indicating studies to determine Lercanidipine $\mathrm{HCl}$ in dosage form. Methods: Optimized chromatographic conditions were achieved by using Symmetry $\mathrm{C}_{18}$ Column, $250 \mathrm{~mm} \times 4.6 \mathrm{~mm}$ and $5 \mu \mathrm{m}$ particle size as stationary phase and Dihydrogen Orthophosphate Buffer: Methanol: $A C N=(40: 40: 20)$ as eluent at flow rate $1.0 \mathrm{ml} / \mathrm{min}$. UV detection was performed at $256 \mathrm{~nm}$. The developed method was validated and stability study was conducted as per ICH guidelines. Results: The retention time was found at $4.778 \mathrm{~min}$. The method shows linearity over a range of $6 \mu \mathrm{g} / \mathrm{ml}$ to $40 \mu \mathrm{g} / \mathrm{ml}$. The obtained correlation coefficient is 0.999. The LOD and LOQ values were 0.09 and $0.27 \mu \mathrm{g} / \mathrm{ml}$. The acidic and alkaline stressed study shows more degradation of $8.181 \%$ and $7.241 \%$.
\end{abstract}

Conclusion: The present developed method was found stability indicating, easy and reliable method can be applied for routine analysis of lercanidipine in bulk drug and the Pharmaceutical formulations.

Key words: Lercanidipine, HPLC, Method development, ICH guidelines, Validation.

\section{Correspondence}

Dr. Sumanta Mondal,

Institute of Pharmacy, GITAM (Deemed to be University), Visakhapatnam, Andhra Pradesh, INDIA.

Phone: +919703615761

Email: mondalresearch@gmail.com

DOI: 10.5530/ijpi.2020.2.36

\section{INTRODUCTION}

Lercanidipineisanantihypertensivedrug. Itbelongsto the dihydropyridine class of calcium channel blockers, which work by relaxing and opening the blood vessels allowing the blood to circulate more freely around the body. This lowers the blood pressure and allows the heart to work more efficiently. ${ }^{1}$ Like other dihydropyridine class calcium channel blockers, lercanidipine blocks L-type calcium channels in the smooth muscle cells of blood vessels, relaxing them and thus lowering blood pressure. In contrast to the non-dihydropyridine calcium channel blockers verapamil and diltiazem, it does not significantly act on calcium channels in the atrioventricular node, and therefore does not decrease heart rate, in usual therapeutic doses. ${ }^{2}$ Lercanidipine is slowly but completely absorbed from the gut. It has a total bioavailability of $10 \%$ due to an extensive first-pass effect, or up to $40 \%$ if taken after a fatty meal. Highest blood plasma levels are reached after 1.5 to 3 hours. The substance is quickly distributed into the tissues and bound to lipid membranes, where it forms a depot. The circulating fraction is almost completely (>98\%) bound to plasma proteins. ${ }^{3,4}$ It is completely metabolized in the liver, mainly via CYP3A4. Elimination half-life is 8 to 10 hours, and the drug does not accumulate. Because of the depot effect, the antihypertensive action lasts for at least 24 hours. 50\% are excreted via the urine ${ }^{5,6}$ Chemically lercanidipine is (RS)-2[(3,3-Diphenylpropyl)(methyl)amino]-1,1-dimethylethyl methyl 2,6-dimethyl-4-(3-nitrophenyl)-1,4-dihydropyridine-3,5-dicarboxylate, ${ }^{7}$ the chemical structure was shown in Figure 1. The extensive literature review on the estimation methods of lercanidipine was conducted as an important part of the present research work to identify the loopholes of the reported methods. It was observed that the lercanidipine was estimated alone or in combination ${ }^{8,9}$ of other antihypertensive agents. The available reported work for the estimation of lercanidipine using HPLC was very few and each of the methods have their own disadvantages, unsatisfactory chromatograms and found ambiguity in several aspects. As of examples one reported method ${ }^{10}$ the linearity was $20-80 \mu \mathrm{g} / \mathrm{mL}$, the lower linearity level is consider very high and questions the sensitivity. In another method ${ }^{11}$ the retention time was reported too long ( 9 minutes). In another reported method ${ }^{12}$ the $\mathrm{pH}$ of the mobile phase maintained 3 , This acidic $\mathrm{pH}$ can be harmful to the shelf life of the analytical column. In an other method reported ${ }^{13}$ the utilization of high amount of acetonitrile (90\%), which is unjustifiable because of its cost. Almost all the reported method has its own disadvantages, therefore it is a need to overcome all the possible unfavourable conditions and to develop a reliable, economic and easy method for the estimation of lercanidipine and to validated ${ }^{14}$ the method as per ICH guidelines.

\section{MATERIALS AND METHODS}

Pharmaceutical grade working standard Lercanidipine $\mathrm{HCl}(99.94 \%$ purity) were obtained from Syncorp Pvt. Laboratories, Hyderabad, India. All chemicals and reagents were HPLC grade and were purchased from S.D. Fine-Chem Limited and Loba Chemie Pvt Ltd, Mumbai, India.

\section{Instrumentation}

The analysis was performed HPLC WATERS with Empower2 Software with Isocratic with UV-Visible Detector., UV-Visible double beam spectrophotometer (T60 LABINDIA), analytical balance $0.1 \mathrm{mg}$ Sensitivity (SHIMADZU), $\mathrm{pH}$ meter (Labindia), ultra sonicator. The 
<smiles>COC(=O)C1=C(C)NC(C)=C(C(=O)OC(C)(C)CN(C)CCC(c2ccccc2)c2ccccc2)C1c1cccc([N+](=O)[O-])c1</smiles>

Figure 1: Chemical structure of lercanidipine.

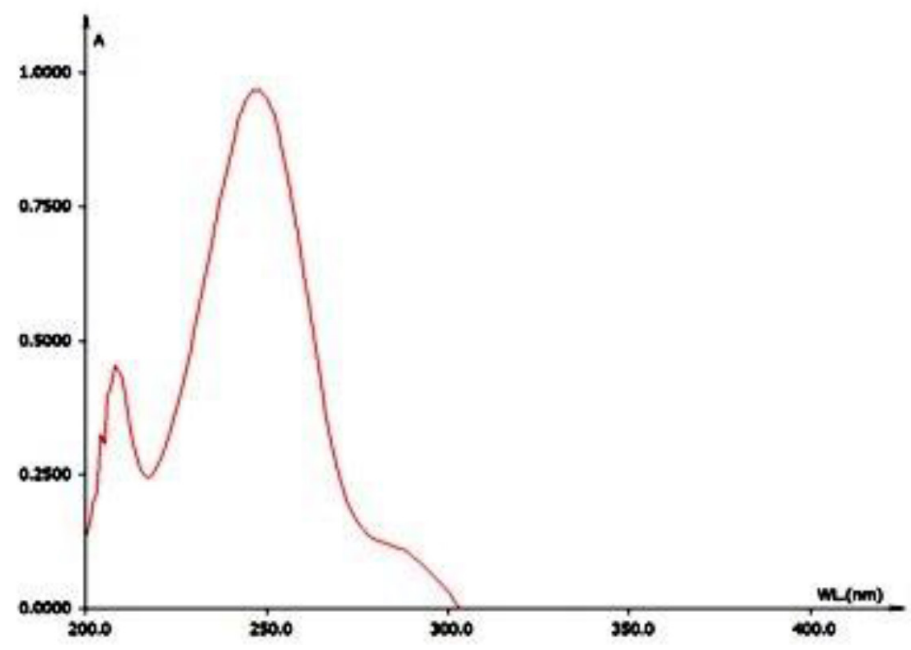

Figure 2: Detection wavelength (UV spectrum) of lercanidipine.

column used is Symmetry $C_{18}$ Column, $250 \mathrm{x} 4.6 \mathrm{~mm}$ and $5 \mu \mathrm{m}$ particle size.

\section{Sample and Standard Preparation for the Analysis}

$10 \mathrm{mg}$ of Lercanidipine hydrochloride standard was transferred into $10 \mathrm{ml}$ volumetric flask, dissolved and make up to volume with mobile phase. Additionally dilution was done by transferring $1 \mathrm{ml}$ of the resulted above solution into a $10 \mathrm{ml}$ volumetric flask and make up the volume up to the mark with the mobile phase

\section{Selection of wavelength}

This has been performed to know the absorption maxima of Lercanidipine $\mathrm{HCl}$, so that the same wave number can be utilized in HPLC UV detector for estimating the Lercanidipine $\mathrm{HCl}$. While scanning the Lercanidipine $\mathrm{HCl}$ solution we observed the maxima at $256 \mathrm{~nm}$ shown in Figure 2.

\section{Preparation of $0.05 \mathrm{M}$ Phosphate buffer Solution}

Exactly weigh about 6.8 grams of Potassium dihydrogen orthophosphate are transferred into a 1 litre of beaker, dissolved and diluted up to $1000 \mathrm{ml}$ with HPLC Grade water.

\section{Preparation of Mobile Phase:}

$400 \mathrm{ml}$ of phosphate buffer, $400 \mathrm{ml}$ of methanol and $200 \mathrm{ml}$ of acetonitrile are mixed well and degassed in ultrasonic water bath for $15 \mathrm{~min}$. The resulted solution was filtered through $0.45 \mu \mathrm{m}$ filter under vacuum filtration. The mobile phase used in this analysis consists of a mixture of $10 \mathrm{mM}$ potassium dihydrogen orthophosphate-methanol-acetonitrile in the ratio of 40: 40: $20(\mathrm{v} / \mathrm{v} / \mathrm{v})$.

\section{Method Validation \\ Accuracy}

To determine the accuracy of the proposed method, recovery studies were carried out by adding different amounts $(80 \%, 100 \%$, and $120 \%)$ of pure drug of Lercanidipine $\mathrm{HCl}$ were taken and added to the pre-analyzed formulation of concentration $100 \mathrm{~g} / \mathrm{ml}$. From that percentage recovery values were calculated.

\section{Precision}

Repeatability

The precision of each method was ascertained separately from the peak areas and retention times obtained by actual determination of Five replicates of a fixed amount of drug. Lercanidipine $\mathrm{HCl}$ (API). The percent relative standard deviation was calculated for Lercanidipine $\mathrm{HCl}$.

\section{Intermediate precision}

The intra and inter day variation of the method was carried out and the high values of mean assay and low values of standard deviation and \% RSD ( $\%$ RSD < 2\%) within a day and day to day variations for Lercanidipine $\mathrm{HCl}$ revealed that the proposed method is precise.

\section{Linearity and Range}

To evaluate the linearity, serial dilution of analyte were prepared from the stock solution was diluted with mobile phase to get a series of concentration ranging from $6-14 \mu \mathrm{g} / \mathrm{ml}$. The prepared solutions were filtered through whatman filter paper (No.41). From these solutions, $10 \mu$ injections of each concentration were injected into the HPLC system and chromatographed under the optimized conditions. Calibration curve was constructed by plotting the mean peak area (Y-axis) against the concentration (X-axis).

\section{Method Robustness}

This method was studied to test the capacity of the developed method to remain stable on the deliberate changes of the various optimised parameters. Influence of small changes in chromatographic conditions such as change in flow rate $( \pm 0.1 \mathrm{ml} / \mathrm{min})$, wavelength of detection $( \pm$ $2 \mathrm{~nm})$ and organic phase content in mobile phase $( \pm 2 \%)$ were studied to determine the robustness of the method.

\section{LOD and LOQ}

This study was determined by using signal to noise approach as defined in ICH guidelines. The LOD and LOQ were assessed at signals to noise ratio of 3:1 and 10:1 respectively by injecting dilute solution of drug was injected into the chromatograph and signal to noise $(\mathrm{S} / \mathrm{N})$ ratio was calculated.

\section{System Suitability Parameter}

System suitability testing is an integral part of many analytical procedures. The tests are based on the concept that the equipment, electronics, analytical operations and samples to be analyzed constitute an integral system that can be evaluated as such. Following system suitability test parameters were established. 


\section{Assay of Lercanidipine $\mathrm{HCl}$ in Pharmaceutical Dosage Form}

Twenty tablets were taken, powdered and triturated well. A quantity of powder equivalent to $100 \mathrm{mg}$ of drugs were transferred to $100 \mathrm{ml}$ volumetric flask, and $70 \mathrm{ml}$ of mobile phase was added and solution was sonicated for 15 minutes, there after volume was made up to 100 $\mathrm{ml}$ with same solvent. Then $10 \mathrm{ml}$ of the above solution was diluted to $100 \mathrm{ml}$ with HPLC grade methanol. The solution was filtered through a membrane filter $(0.45 \mu \mathrm{m})$ and sonicated to degas. From this stock solution $(1.0 \mathrm{ml})$ was transferred to five different $10 \mathrm{ml}$ volumetric flasks and volume was made up to $10 \mathrm{ml}$ with same solvent system. The solution prepared was injected in five replicates into the HPLC system and the observations were recorded. A duplicate injection of the standard solution was also injected into the HPLC system and the peak areas were recorded. Results obtained are tabulated below.

\section{Stability studies}

The API (Lercanidipine $\mathrm{HCl}$ ) was subjected to stress conditions in various ways to observe the rate and extent of degradation that is likely to occur in the course of storage and/or after administration to body. The various degradation pathways studied are acid hydrolysis, basic hydrolysis, thermal degradation, photolytic degradation and oxidative degradation. Acid degradation: The API was exposed to acidic conditions by using $30 \mathrm{ml}$ of $0.1 \mathrm{~N} \mathrm{HCl}$ and was refluxed in a water bath at $60^{\circ} \mathrm{C}$ for 4 hours. Basic degradation: The API was exposed to acidic conditions by using $30 \mathrm{ml}$ of $0.1 \mathrm{~N} \mathrm{NaOH}$ and was refluxed in a water bath at $60^{\circ} \mathrm{C}$ for 4 hours. Thermal degradation: The drug was mixed with water and refluxed in a water bath at $60^{\circ} \mathrm{C}$ for $6 \mathrm{hrs}$ uninterruptedly. Photolytic degradation: $10 \mathrm{mg}$ of pure drug was taken in a clean and dry Petri dish. It was kept in a UV cabinet at $254 \mathrm{~nm}$ wavelength for $24 \mathrm{hrs}$ without interruption Oxidative degradation: The drug was exposed to oxidative degradation conditions by using $3 \% \mathrm{H}_{2} \mathrm{O}_{2}$ and then kept as such in dark for $24 \mathrm{hrs}$. For all the degradation conditions the final concentration was prepared to $100 \mu \mathrm{g} / \mathrm{ml}$ with mobile phase and was injected into the HPLC system.

\section{RESULTS}

To develop a precise, linear, specific stability indicating RP-HPLC method for analysis of Lercanidipine $\mathrm{HCl}$, different chromatographic conditions were applied. Isocratic elution was preferred for the current study. In case of RP-HPLC various columns are available, but here Symmetry, $\mathrm{C}_{18}$, 250x 4.6 mm.i.d., 5m Particle size column was preferred because using this column peak shape, resolution and absorbance were good. Mobile phase and diluent for preparation of various samples were finalized after studying the solubility of API in different solvents of our disposal (methanol, acetonitrile, dichloromethane, water, $0.1 \mathrm{~N} \mathrm{NaOH}, 0.1 \mathrm{NHCl}$ ). The retention time was found at 4.778 mins shown in Figure 3.

In the study of linearity, the calibration curve showed good linearity in the range of $6-40 \mu \mathrm{g} / \mathrm{ml}$, for Lercanidipine (API) with correlation

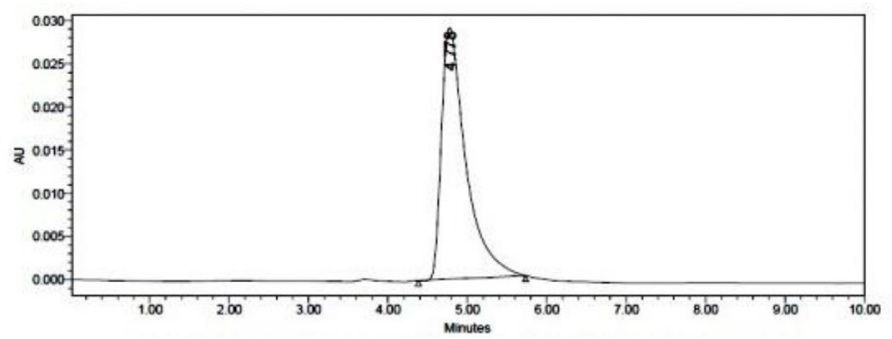

Figure 3: Optimised chromatogram of lercanidipine. coefficient $\left(R^{2}\right)$ of 0.999 . A typical calibration curve has the regression equation of $\mathrm{y}=11401 \mathrm{x}-7400$ for Lercanidipine $\mathrm{HCl}$. The results were summarised in Table 1. From the accuracy method, it was observed that the mean \%recovery of the drug are $101.436,101.55$ and 100.23 which is within the range of $98-102 \%$ and $\%$ RSD is within the range $<2$ i.e. $0.079 \%, 1.041 \%$ and $0.780 \%$ respectively, as shown in Table 2 . In the study of precision the $\%$ RSD for repeatability was found for repeatability is 0.330 , for intraday study it was 0.74 and for interday it was 0.175 . The Minimum concentration level at which the analyte can be reliable detected (LOD) and quantified (LOQ) were found to be 0.09 and $0.27 \mu \mathrm{g} / \mathrm{ml}$ respectively, the results were summarised in Table 1 . The assay of Lercanidipine $\mathrm{HCl}$ Tablets (Actavis) containing lercanidipine was found to be $99.85 \%$, shown in Table 3 . The robustness study of the method was carried out by changing three parameters from the chromatographic conditions such as changes in mobile phase composition $( \pm 2 \%)$, changes in flow rate $( \pm 0.1 \mathrm{ml} / \mathrm{min})$, and detection wavelength $( \pm 2 \mathrm{~nm})$ and the \% RSD of the tailing factor was calculated found to be less than 2.0 as shown in Table 4. The results of the stress degradation studies show that in acidic, alkaline and UV irradiation some degradation was

Table 1: Summary of validation parameters.

\begin{tabular}{cc}
\hline Parameters & Results \\
\hline Beer's law limit in $\mathbf{g} / \mathbf{m l}$ & $6-40$ \\
Co-relation co-efficient & 0.999 \\
LOD g/ml & 0.09 \\
LOQ g/ml & 0.27 \\
Repeatability (\% RSD) & 0.330 \\
Interday Precision (\% RSD) & 0.74 \\
Intraday Precision (\%RSD) & 0.175 \\
\hline
\end{tabular}

Table 2: Accuracy Readings of lercanidipine

\begin{tabular}{cccccc}
\hline $\begin{array}{c}\text { Sample } \\
\text { ID }\end{array}$ & $\begin{array}{c}\text { Concentration } \\
(\mu \mathrm{g} / \mathrm{ml})\end{array}$ & $\begin{array}{c}\text { Peak } \\
\text { Area }\end{array}$ & $\begin{array}{c}\% \text { Recovery } \\
\text { of Pure } \\
\text { drug }\end{array}$ & $\begin{array}{c}\text { Statistical } \\
\text { Analysis }\end{array}$ \\
\hline & $\begin{array}{c}\text { Amount } \\
\text { Added }\end{array}$ & $\begin{array}{c}\text { Amount } \\
\text { Found }\end{array}$ & & & \\
\hline $\mathrm{S}_{1}: 80 \%$ & 8 & 8.04 & 99136 & 100.5789 & Mean $=100.55 \%$ \\
$\mathrm{~S}_{2}: 80 \%$ & 8 & 8.05 & 99180 & 100.6271 & S.D. $=0.08$ \\
$\mathrm{~S}_{3}: 80 \%$ & 8 & 8.03 & 99030 & 100.4627 & $\%$ R.S.D. $=0.079$ \\
$\mathrm{~S}_{4}: 100 \%$ & 10 & 10.01 & 121600 & 100.1666 & Mean $=100.77 \%$ \\
$\mathrm{~S}_{5}: 100 \%$ & 10 & 10.01 & 121598 & 100.1649 & S.D. $=1.05$ \\
$\mathrm{~S}_{6}: 100 \%$ & 10 & 10.19 & 123689 & 101.9989 & $\%$ R.S.D. $=1.041$ \\
$\mathrm{~S}_{7}: 120 \%$ & 12 & 12.14 & 145901 & 101.2345 & Mean $=101.17 \%$ \\
$\mathrm{~S}_{8}: 120 \%$ & 12 & 12.23 & 146852 & 101.9297 & S.D. $=0.79$ \\
$\mathrm{~S}_{9}: 120 \%$ & 12 & 12.04 & 144687 & 100.3472 & $\%$ R.S.D $=0.780$ \\
\hline
\end{tabular}

Table 3: Assay of lercanidipine Tablets.

\begin{tabular}{cccc}
$\begin{array}{c}\text { Brand name of } \\
\text { tablets }\end{array}$ & $\begin{array}{c}\text { Labelled } \\
\text { amount of Drug } \\
(\mathrm{mg})\end{array}$ & $\begin{array}{c}\text { Mean (SD) amount } \\
(\mathrm{mg}) \text { found by the } \\
\text { proposed method } \\
(\boldsymbol{n}=6)\end{array}$ & $\begin{array}{c}\text { Mean (SD) } \\
\text { Assay }(\boldsymbol{n}=6)\end{array}$ \\
\hline $\begin{array}{c}\text { Lercanidipine } \\
\text { HCl Tablets } \\
\text { (Actavis) }\end{array}$ & 20 & $19.86(0.453)$ & $99.85(0.086)$ \\
\hline
\end{tabular}


Table 4: Results of method Robustness Test.

\begin{tabular}{cc}
\hline Change in parameter & $\%$ RSD \\
\hline Flow $(1.1 \mathrm{ml} / \mathrm{min})$ & 0.09 \\
Flow $(0.9 \mathrm{ml} / \mathrm{min})$ & 0.56 \\
More Organic $(+2 \%)$ & 0.12 \\
Less Organic $(-2 \%)$ & 0.19 \\
Wavelength of Detection $(258 \mathrm{~nm})$ & 0.44 \\
Wavelength of detection $(254 \mathrm{~nm})$ & 0.42 \\
\hline
\end{tabular}

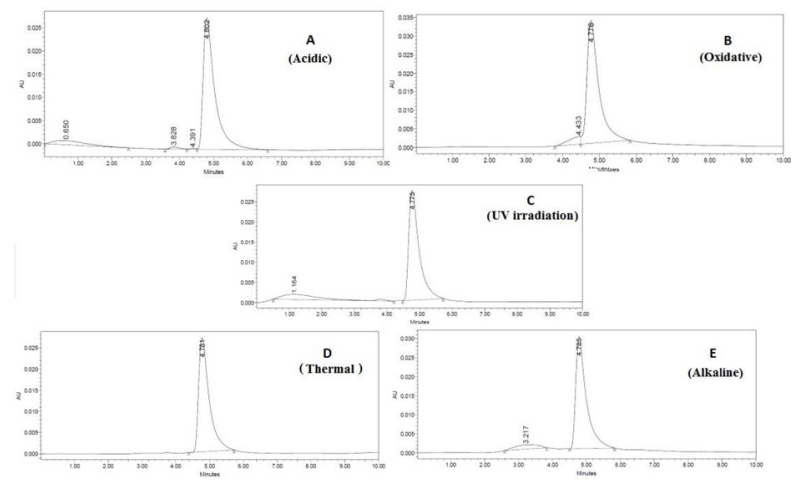

Figure 4: Force degradation study of lercanidipine.

Table 5: Results of stressed degradation study.

\begin{tabular}{ccccc} 
Stress condition & Time & $\begin{array}{c}\text { Assay of } \\
\text { active } \\
\text { substance }\end{array}$ & $\begin{array}{c}\text { Assay of } \\
\text { degraded } \\
\text { products }\end{array}$ & $\begin{array}{c}\text { Mass } \\
\text { Balance } \\
(\%)\end{array}$ \\
\hline $\begin{array}{c}\text { Acid Hydrolysis } \\
(0.1 \mathrm{M} \mathrm{HCl})\end{array}$ & $24 \mathrm{Hrs}$. & 91.819 & 8.181 & 100.0 \\
$\begin{array}{c}\text { Basic Hydrolysis } \\
(0.1 \mathrm{M} \mathrm{NaOH})\end{array}$ & $24 \mathrm{Hrs}$. & 92.759 & 7.241 & 100.0 \\
$\begin{array}{c}\text { Thermal Degradation } \\
\left(60^{\circ} \mathrm{C}\right)\end{array}$ & $24 \mathrm{Hrs}$. & 99.229 & 0.771 & 100.0 \\
$\begin{array}{c}\text { UV }(256 \mathrm{~nm}) \\
\text { 3 } \% \text { Hydrogen peroxide }\end{array}$ & $24 \mathrm{Hrs}$. & 98.529 & 1.471 & 100.0 \\
\hline
\end{tabular}

happen. In acidic stressed condition $8.18 \%$, In alkaline stressed condition $7.241 \%$ and in UV irradiation it was $1.471 \%$. Thermal degradation and oxidative degradation the values were $0.771 \%$ and $0.841 \%$. The chromatograms of various stressed conditions were shows in Figure 4 and the results were summarised in Table 5 .

\section{DISCUSSION}

In the present research work the optimised chromatographic conditions was confirmed after several trials. By utilizing the developed optimised condition lercanidipine eluted with a satisfactory peak shape, very short retention time using a mixture of dihydrogen orthophosphate buffer : methanol : acetonitrile in a ratio of $40: 40: 20$ and flow rate was optimised as $1.0 \mathrm{ml} /$ minute, at the wavelength of wavelength $256 \mathrm{~nm}$, run time was 10 mins. Here the peaks were separated and showed better resolution, theoretical plate count and symmetry. The proposed chromatographic conditions were found appropriate for the quantitative determination of the drug. The detail study results of validation parameters clearly justified the developed method and its applicability in marketed dosage form. The all results were found within acceptance criteria. ${ }^{15}$ Precision and accuracy were determined as per the ICH guidelines and the \% recovery was found within the acceptable limit i.e. not more than $2.0 \%$, indicated the accuracy of the developed method. In repeatability study the amount found was calculated and \%RSD was found satisfactory and within the limit. The results of precision study indicated that the developed method was found precise. In the linearity study of the developed method the correlation coefficient was found near to 0.999 for lercanidipine which indicates its specified linearity. The least squares method was used to establish the regression line and the curves were linear. The average percentage assay $99.85 \%$ was considered within the limit and found suitable to analyse using developed method for the estimation of lercanidipine in marketed dosage form The limit of detection and quantitation values proves the effectiveness and sensitivity of the developed method. In the specificity study no excipients peaks were found at the retention time of the analyte and indicates the specificity of the method. In robustness study the tailing factor was considered and the \% RSD of the tailing factor was found less than 2.0 as shown in robustness table, which proved the robustness of the developed method, because no such significant changes were found on deliberate changes in the optimised parameters. Degradation studies results of lercanidipine indicated that acidic and alkaline stressed condition leads to little more degradation in compare to other stressed condition, but in every studied stressed condition the lercanidipine was eluted specifically.

\section{CONCLUSION}

The data and information concerning drugs, reagents and techniques given in results and discussion reveal that the proposed methods are simple, selective, sensitive (some are superior to the other methods) and accurate with reasonable precision. In addition, selectivity to each selected drug in its formulations was achieved by selecting the appropriate combination of solvent systems, acids or bases in sample solution preparation and exploiting specific functional groups exclusively present in the drug but not in the excipients, additives or other active ingredient present in the formulations, to the extent possible. The proposed method can be used to reported ones and provide a wide choice for the routine determination of the above-mentioned drug depending upon the availability of chemicals and situation arising due to the presence of concomitants.

\section{ACKNOWLEDGEMENT}

The authors are thankful to the GITAM Institute of Pharmacy, Visakhapatnam, for providing the necessary facilities to carry out the research work.

\section{CONFLICT OF INTEREST}

The authors declare no conflict of interest.

\section{ABBREVIATIONS}

RP HPLC: Reverse phase High performance liquid chromatography; LOD: Limit of detection; LOQ: Limit of quantitation; RSD: Relative standard deviation; UV: Ultra violet; ICH: International conference on Harmonization.

\section{REFERENCES}

1. Barrios V Escobar C, Navarro A, Barrios L, Navarro-Cid J, Calderón A Lercanidipine is an effective and well tolerated antihypertensive drug regardless the cardiovascular risk profile: The LAURA study. Int J Clin Pract. 2006;60(11):1364-70

2. Herbette LG, Vecchiarelli M, Sartani A, Leonardi A. Lercanidipine: short plasma half-life, long duration of action and high cholesterol tolerance. Updated molecular model to rationalize its pharmacokinetic properties. Blood Press Suppl. 1998;2:10-7 
3. Bang LM, Chapman TM, Goa KL. Lercanidipine. A Review of Its Efficacy in the Management of Hypertension. Drugs. 63(22) 2449-72.

4. Meredith PA. Lercadinidipine: a novel lipophilic dihydropyridine calcium antagonist with long duration of action and high vascular selectivity. Exp Opin Invest Drugs. 1999;8:1043-62.

5. Gasser R, Köppel H, Klein W. Lercanidipine, a new third generation C-antagnist in the treatment of hypertension. J Clin Basic Cardiol. 1999;2:169-74.

6. Cherubini A, Fabris F, Ferrari E, et al. Comparative effects of lercanidipine, lacidipine, and nifedipine gastrointestinal therapeutic system on blood pressure and heart rate in elderly hypertensive patients: the ELderly and Lercanidipine (ELLE) study. Arch Gerontol Geriatr. 2003;37:203-12.

7. Vincent J, Harris SI, Foulds G, Dogolo LC. Willavize S Friedman HL. Lack of effect of grapefruit juice on the pharmacokinetics and pharmacodynamics of amlodipine. British J Clin Pharmacol. 2000;50(5):455-63.

8. Deepak KJ, Pratibha P, Abu SK. Development and Validation of a RP-HPLC Method for The Simultaneous Estimation of Atenolol and Lercanidipine Hydrochloride in Pharmaceutical Dosage forms. Int $\mathrm{J}$ Chem tech Res. 2013;3(2):766-71.

9. Eboka MB, Janvier SM, Zhang A. Simultaneous Determination of Fixed-Dose
Combination of Lercanidipine and Valsartan in Human Plasma by LC-MS-MS Application to a Pharmacokinetic Study. J Chromatogr Sci. 2016;54(9)234-9.

10. Kaila HO, Ambasana MA, Thakkar RS, Saravaia HT. A Stability-Indicating HPLC Method for Assay of Lercanidipine Hydrochloride in Tablets and For Determining Content Uniformity. Ind J Pharm Sci. 2010;72(3):381-4.

11. Mubeen G, Mamta P, Vimala Mn. HPLC Method for Analysis of Lercanidipine Hydrochloride in Tablets. Int J Pharm Bio Sci. 2010;4(1):34-42.

12. Mihaljica S, Radulovic D, Trbojevic J. Determination of Lercanidipine Hydrochloride and its Impurities in Tablets. Int J Rap Commun Chromatogr. 2005;61:54-63

13. Ankita DC, Renuka SM, Josyula VR. Development and Validation of Reversed Phase High-Performance Liquid Chromatography Method for Estimation of Lercanidipine $\mathrm{HCl}$ in Pure Form and from Nanosuspension Formulation. J Basic Clin Pharm. 2015;7(1):17-22.

14. Mondal P, Shobharani S, Ramakrishna R. Novel stability indicating validated RPHPLC method for simultaneous quantification of Artemether and Lumefantrine in Bulk and Tablet. Curr Pharm Anal. 2014;10(4):271-8.

15. Mondal P, Mahender K, Padmaja B. A Novel UPLC-PDA Method for the Simultaneous Determination of Lamivudine, Zidovudine and Nevirapine in Bulk and Tablet Dosage Form. Anal. Chem. Let. 2018;8(1):131-8.

Article History: Submission Date : 12-02-2020; Revised Date : 29-02-2020; Acceptance Date : 18-03-2020.

Cite this article: Mondal S, Pushpalatha R, Mondal P, Mahapatra AS, Shit D, Das AK and Biswal S. A Stability Indicating Validated Method for the Determination of Lercanidipine Using Reverse Phase High Performance Liquid Chromatography. Int. J. Pharm. Investigation. 2020;10(2):197-201. 